\title{
THE ANALYSIS OF CRANE DRUM BRAKE'S FRICTIONAL BEHAVIOR BASED ON ADAMS
}

\author{
Haixiang $\mathrm{Xu}^{1, \mathrm{a}}$, Fengqi $\mathrm{Wu}^{1, \mathrm{~b}}$ \\ Shanghai Special Equipments Inspection \& Technical Research Institute, \\ No.399, Nujiang NorthRoad, Shanghai, China, 200333 \\ axuhx@ssei.cn, bufq@ssei.cn
}

\begin{abstract}
Keywords: Virtual Prototype, ADAMS, Type test of braker
Abstract. Through analysis of basic working principle of crane drum brake, change of friction factor under the influence of relative sliding speed, load and other factors is analyzed. Combined with the static and dynamic braking torque experimental results, the Rigid body and rigid flexible coupling model of drum brake virtual prototype are adopted to simulate its fictional behavior by ADAMS dynamic analysis software, which satisfies the realistic condition of static and dynamic frictional coefficients and lays a foundation for the study and design of drum brake.
\end{abstract}

\section{Introduction}

As one of the most important safety equipment, the crane drum brake has the function of stopping the hoisting and travelling mechanism and guaranteeing that the lifting load can be accurately decelerated and braked. It is not only the control device of crane, but also the safety equipment to protect the operation of crane. The performance of drum brake is determined by many factors, such as the friction coefficient of frictioNmaterials, temperature, the smoothness of contact surfaces, the vibration of brake during braking, the influence of complex environment etc. Though the researchers spend a lot of manpower and material resources on experimental research of drum brake, some of the phenomenon is also difficult to reproduce.

With the fast development of CAE/CAM/CAD technology, the drum brake can be analyzed on the base of these softwares. By the ADAMS dynamic simulation software, Ning X.B.[1][2] etc. have developed the connectioNmodule of flexible friction lining, grid brake shoes and grid drum, built the nonlinear grid-flexible couple simulatioNmode of mine truck drum brake, then calculated brake efficiency factor. Lü Z.H. etc. [3] have deduced uneven index calculation formula and analyzed its characteristic by defining two uneven indexes of the pressure on friction plate, which is as the new evaluation index to assess various types of drum brake, they have put forward that braking efficiency can be significantly improved by dividing the braking shoes into two mutual interaction structure types. The relation between friction lining sheet and drum belongs to typical frictional contact problems, and through the finite element analysis method, the contact stress distribution can be obtained, which is hard to measure by experiment. Mao Z.D. etc.[4] have established the finite element model of drum brake by ANSYS, analyzed the contact stress between the friction lining sheet and drum, obtained the contact stress distribution characteristics and the brake stress field distribution, the results show that the analysis is accuracy enough for the design in theoretical guidance. But all above is about the car's brake, while the brake of crane is less researched.

In the paper, the type of crane drum brake discussed is YWZ5-630/301, and the diameter of drum is $630 \mathrm{~mm}$, the matched brake booster is Ed301/6, the rated braking torque is $6330 \mathrm{Nm}$. According to the rule of type test[5], the static braking torque is no less than the rated torque, and the static braking torque is $7100 \mathrm{Nm}$ in field test, which satisfies the requirement of type test rule, meanwhile, the mean dynamic braking torque is no less than 0.9 times the rated torque, so the dynamic torque is $5800 \mathrm{Nm}$ in field test, which also satisfies the requirement of type test rule. 


\section{The static braking torque simulation of crane drum brake}

The static braking torque test is an important item in crane brake type test, it is to verify whether the static braking torque is bigger than that of the rated brake. As to the operation of crane, only sufficient large static braking torque about crane brake can prevent the weight from falling down when the crane holds it from one place to the other. This test is carried on the device as Fig. 1, when the torque generated by the leverage and the lever exceeds the static braking torque of the brake, the drum is rotated, then the static braking torque is equal to the latest leverage before rotation plus the length of lever. In this simulation, the virtual prototype of drum brake is constructed as Fig. 2, and some constraints are added to realize its parts' relative motions, such as the contact between the drum and brake-shoes, the revolute joint between left(right) arm and base, the brake-shoes and left(right) brake arm. For the static braking torque test is micro movement, the damping of the spring can be omitted, therefore, the spring is replaced as the equal force with the same motion, and the spring force is measured on the spring testing machine at the corresponding compress length, which is $4580.8 \mathrm{~N}$. In order to analyze the influence of part's deformations on the static friction coefficient, three different models are compared in the paper, they are the rigid body, the flexible drum and flexible brake-shoes models individually, which is shown in Fig. 2, Fig. 3 and Fig. 4.

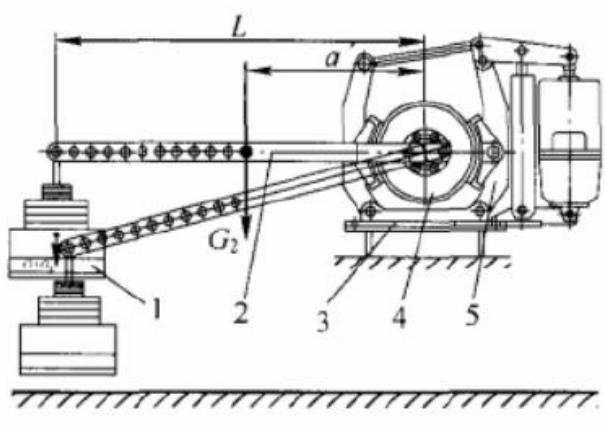

Figure 1. principle of measure static torque

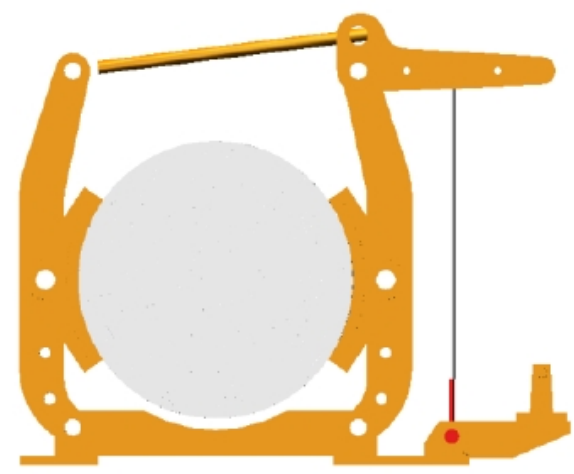

Figure 3. the flexible drum model

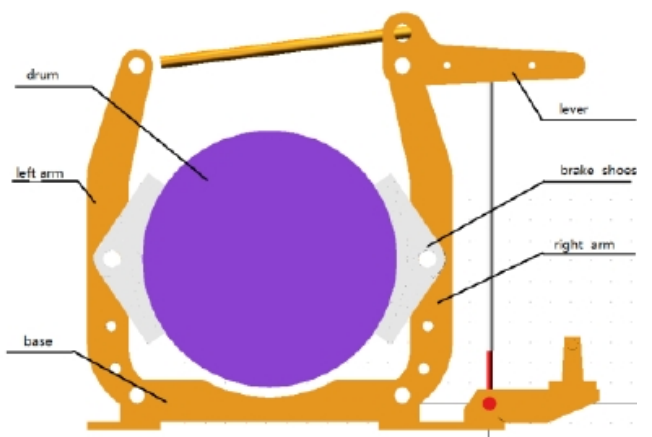

Figure 2. the rigid model of drum brake

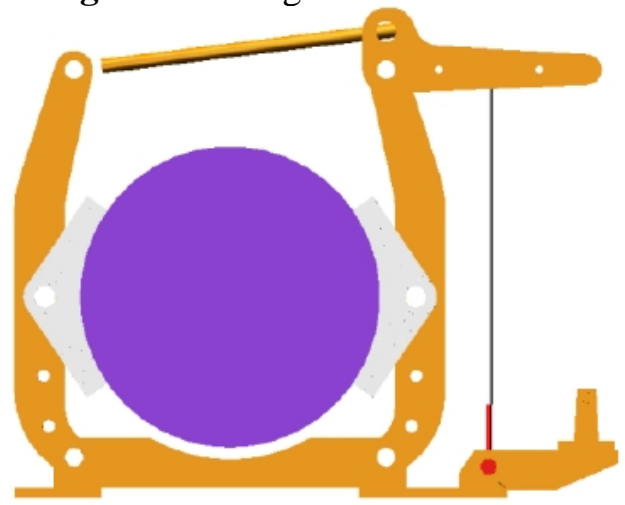

Figure 4. the flexible brake shoes model

The flexible drum and brake shoes are generated in Patran finite element analysis software by dividing the entity grid and adding the MPC constraint on the solid parts' model, which is shown in Fig. 5 and Fig. 6, then the normal modes solution is executed to obtain the parts' vibratioNmodes at different frequencies with nmf files, therefore, the rigid-flexible models are generated individually by importing nmf files to ADAMS, at the same time, the lower frequencies of flexible body are omitted for they represent grid body mode. Only 7th-18th modes are chosen in the rigid flexible coupling model. 


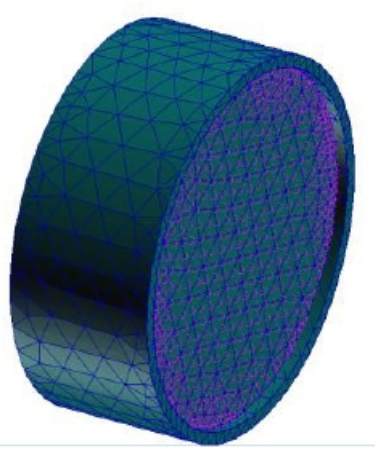

Figure 5. the drum model

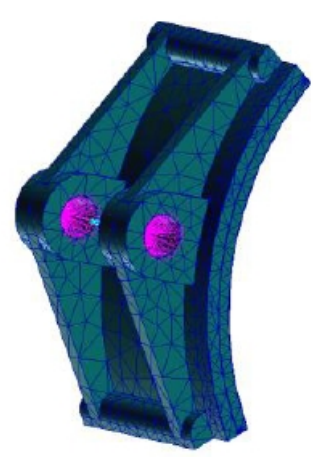

Figure 6. the brake shoes model

In order to accurately find the static friction coefficient in simulation, the static coefficient of contact in ADAMS is set among 0.9 to 0.35 , and $7200 \mathrm{Nm}$ that is slightly larger than the measured static braking torque be on the brake drum. When the static coefficient of contact is lower than needed, the drum is rotated by the external torque, then the measured static braking torque as $7100 \mathrm{Nm}$ is on the brake drum, in order to prevent the drum from rotating, the static coefficient of contact is adjusted to the critical value on the basis of the previously simulation, and the driven torque function is STEP(time,6,0,7,7200000), meanwhile, an angle sensor is aligned on the drum, which makes it convenient to determine whether the drum is rotated.

In the rigid body model simulation, the angles varied with different static friction coefficients at $7200 \mathrm{Nm}$ is shown in Fig. 7, when static friction coefficients are greater than 0.35 , angles of drum are almost kept stable. During 6s-7s, the angle curves are fluctuated due to the external torque. Then by simulation the minor static friction coefficients to keep drum stable is 0.349 at $7100 \mathrm{Nm}$, the positive force and friction force on the drum are shown in Fig. 8 and Fig. 9 respectively, in Fig. 8 the positive forces are varying from $32500 \mathrm{~N}$ to $27500 \mathrm{~N}$ due to the external torque. Similarly, the friction forces are varying from almost $0 \mathrm{~N}$ to $13263 \mathrm{~N}$ and $12092 \mathrm{~N}$, which aren't equal because the drum's weight is also considered.

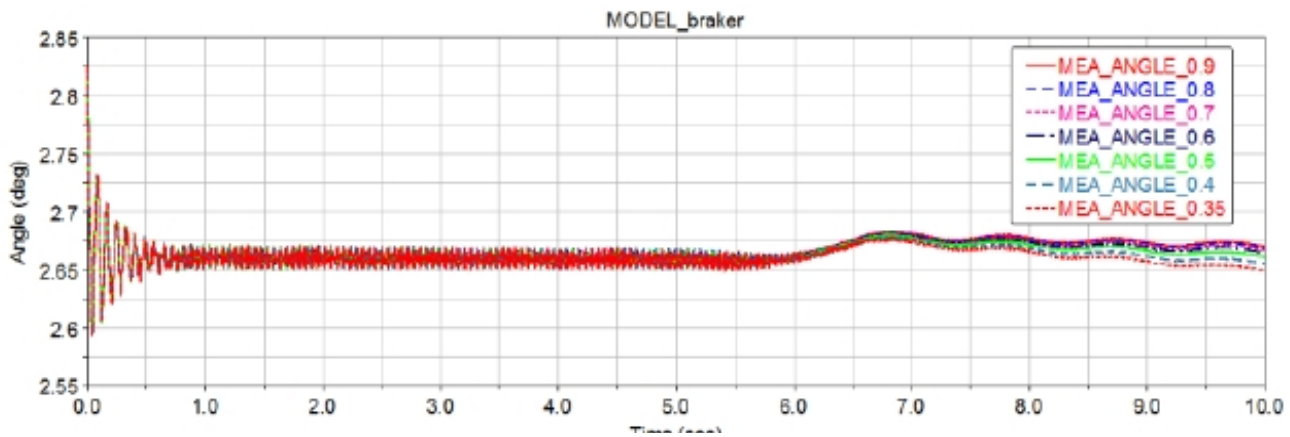

Figure 7. the angles varied with different static friction coefficients

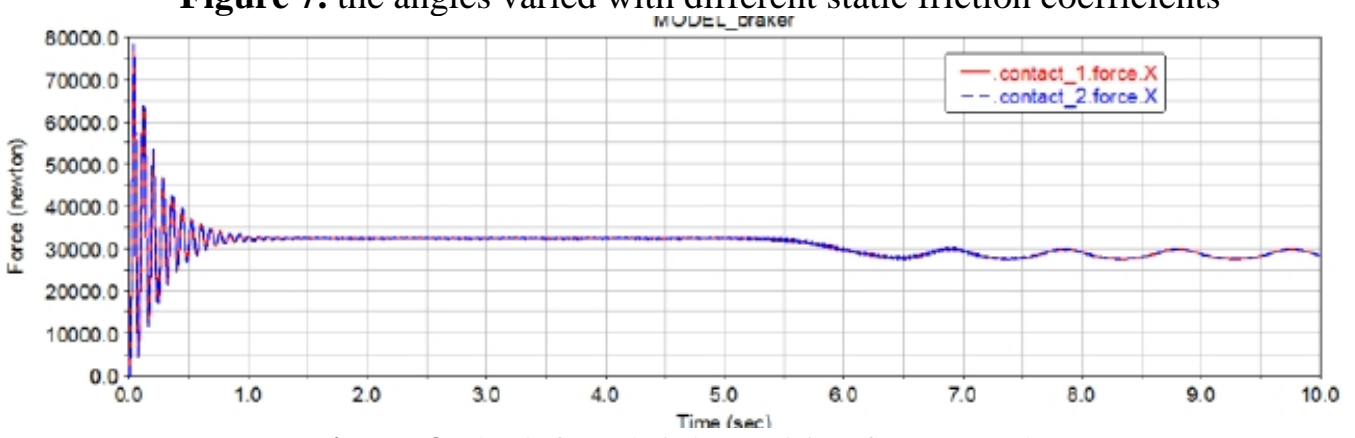

Figure 8. the left and right positive forces on drum 


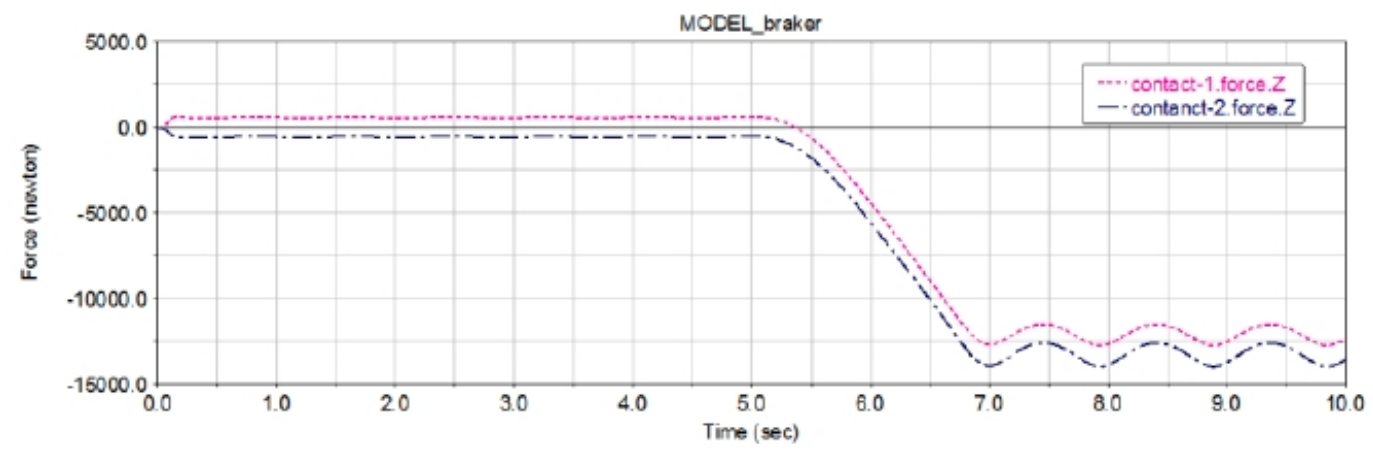

Figure 9. the left and right friction forces on drum

Similarly, as to two rigid flexible coupling models, when the brake shoe is flexible body, the minor static friction coefficients to keep drum stable is 0.375 at $7100 \mathrm{Nm}$, the positive forces and the friction forces on drum are shown in Fig. 10 and Fig. 11, in Fig. 10 the positive forces are rising from $32300 \mathrm{~N}$ to $32500 \mathrm{~N}$ during the external torque being executed, in figure 11 the two friction forces are eventually stabilized at $11280 \mathrm{~N}$. When the drum is flexible body, the minor static friction coefficients to keep drum stable is 0.65 at $7100 \mathrm{Nm}$, the positive forces and the friction forces on drum are shown in Fig. 12 and Fig. 13, in Fig. 12 the positive forces are rising from $32000 \mathrm{~N}$ to $32500 \mathrm{~N}$ during the external torque being executed, in Fig. 13 the two friction forces are eventually equal at 10560N.

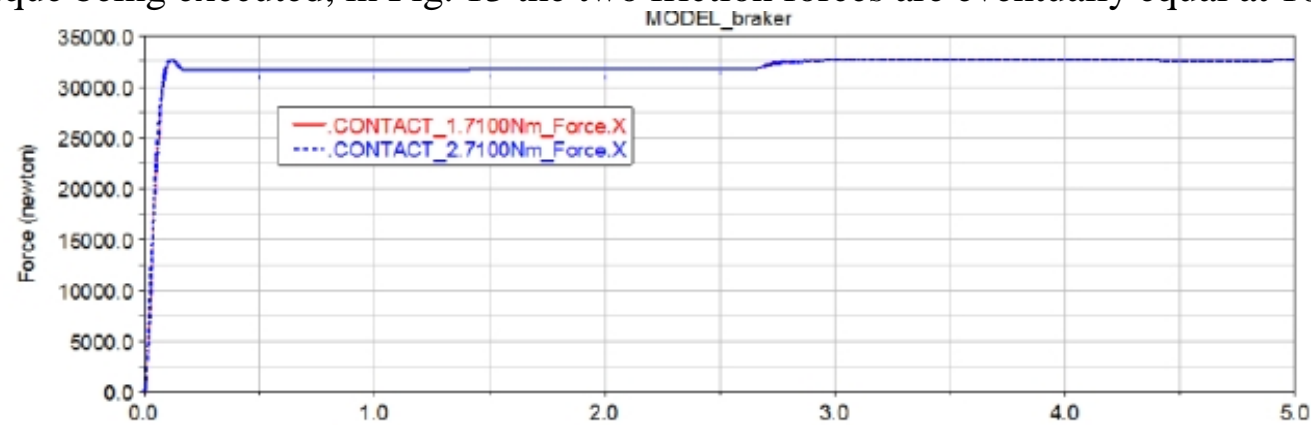

Figure 10. the positive forces on drum (flexible brake shoes )

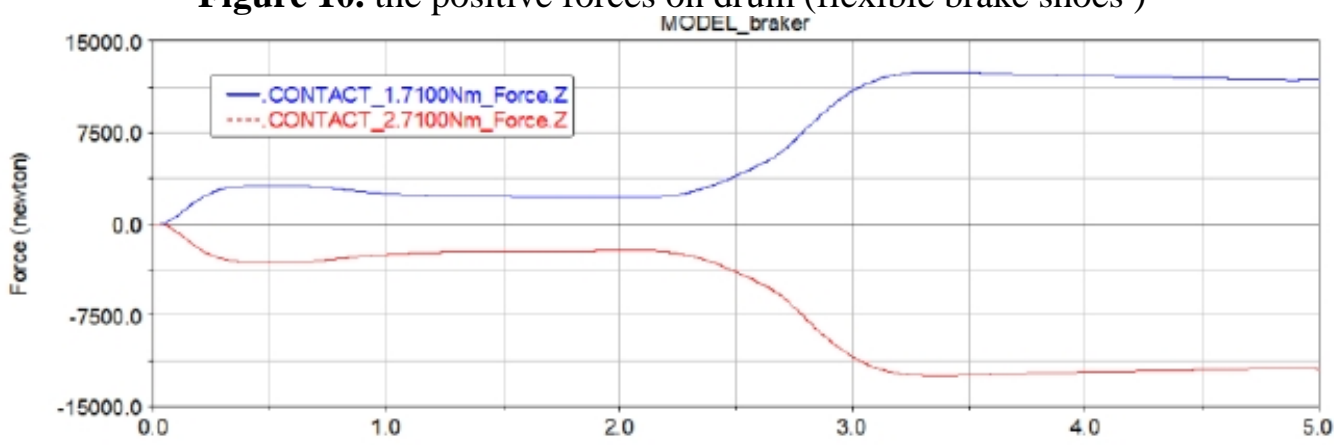

Figure 11. the friction forces on drum (flexible brake shoes)

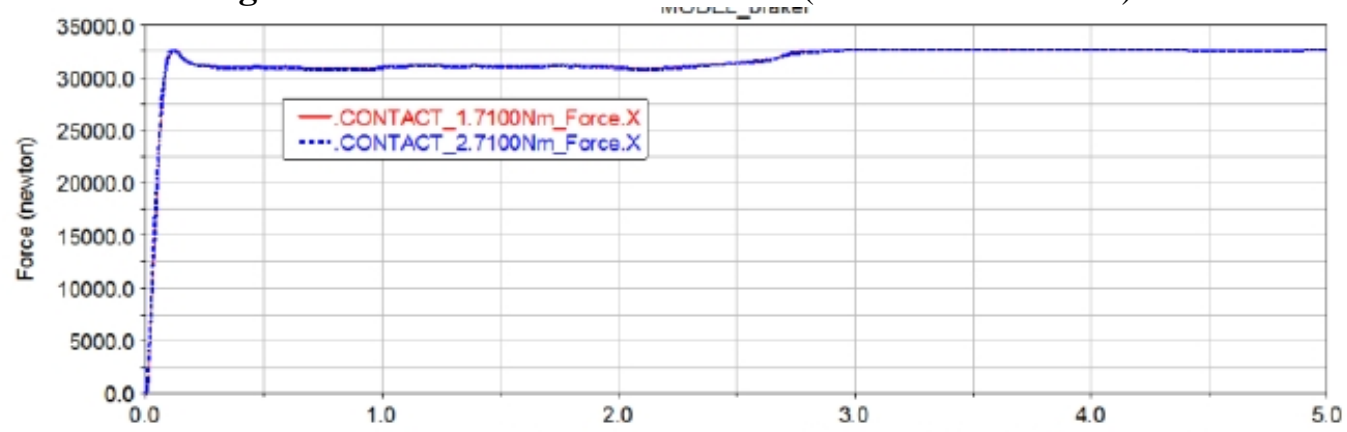

Figure 12. the positive forces on drum (flexible drum) 


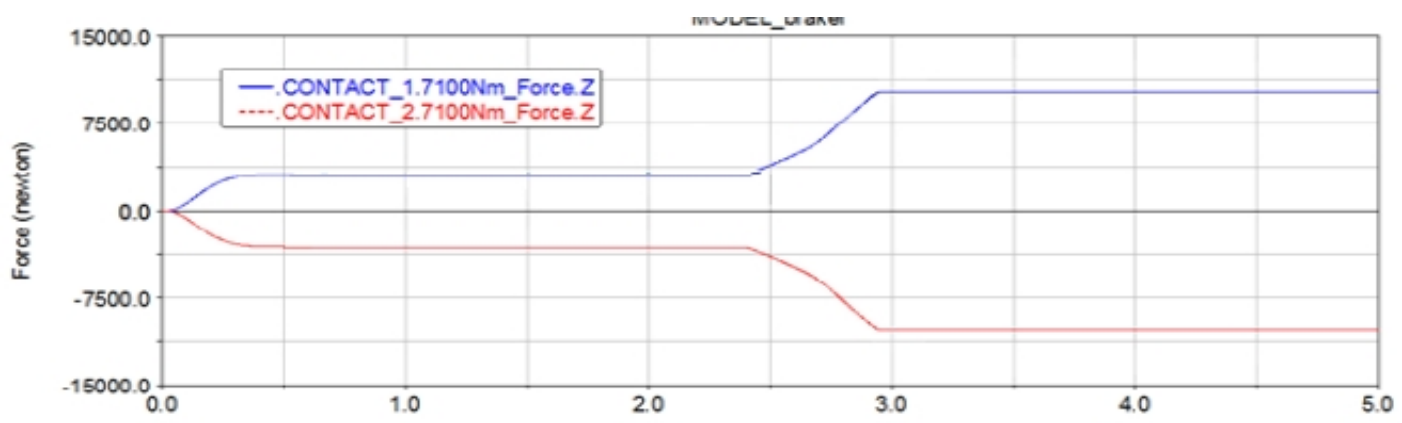

Figure 13. the friction forces on drum(flexible drum)

The comparison of three different models is presented at Table 1, where the static friction coefficient of flexible brake shoes model is 0.375 , it is the closest to the experimental friction coefficient of material at ambient temperature in test reporter. As to the friction torque, the flexible brake shoes model is also the closest to the external torque $7100 \mathrm{Nm}$. The simulation result of flexible brake shoes model is the most closely consistent with the experiment of static braking torque, and in the rigid body model the deformation of contact friction pairs isn't considered, while in the flexible drum model the deformation of drum is considered, but the deformation of brake shoes isn't taken consider, the deformation of brake shoes is bigger than that of drum in the experiment.

Table 1. the summary of the static braking torque

\begin{tabular}{|c|c|c|c|c|}
\hline the model type & $\begin{array}{c}\text { static friction } \\
\text { coefficient }\end{array}$ & $\begin{array}{c}\text { friction force } \\
(\mathrm{N})\end{array}$ & $\begin{array}{c}\text { Friction torque } \\
(N \bullet m)\end{array}$ & $\begin{array}{c}\text { positive force } \\
(\mathrm{N})\end{array}$ \\
\hline rigid model & 0.349 & 12678 & 7986.8 & 27500 \\
\hline $\begin{array}{c}\text { flexible brake } \\
\text { shoes model }\end{array}$ & 0.375 & 11280 & 7106.4 & 32500 \\
\hline $\begin{array}{c}\text { flexible drum } \\
\text { model }\end{array}$ & 0.65 & 10560 & 6652.8 & 32500 \\
\hline
\end{tabular}

\section{The dynamic braking torque simulation of crane drum brake}

In the crane brake type test, the dynamic braking torque is measured by the inertia test system, which is shown in Fig. 14, and the virtual prototype of inertia test system is shown in Fig. 15, two revolve joints are added at each end of main shaft, the flywheels needed in the simulation are attached to main shaft with fixed joints, while the other are fixed on the ground. The brake drum is fixed oNmain shaft, and the base of brake is also fixed on the ground, and the parts' mass and moment of the inertia are set in ADAMS according to their drawing.

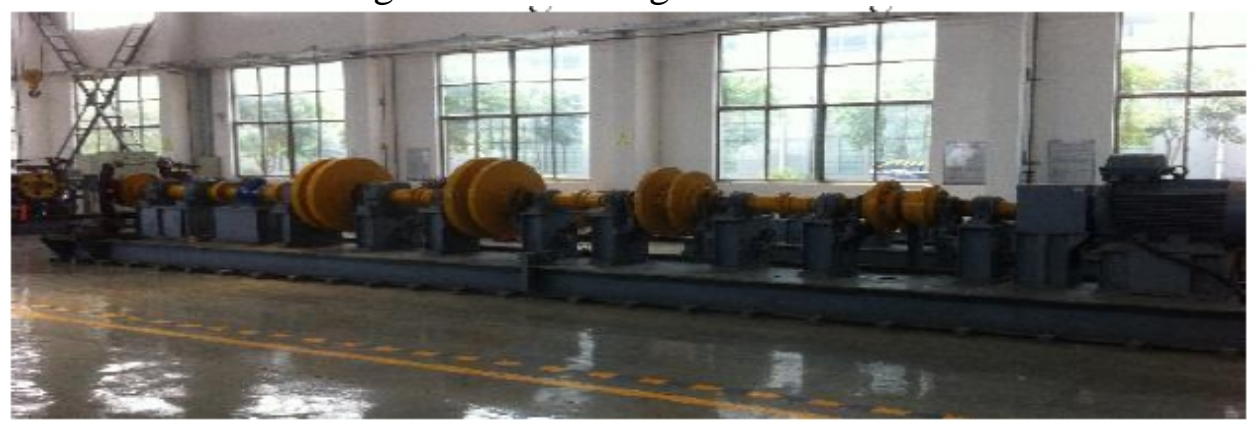

Figure 14. the inertia test system 


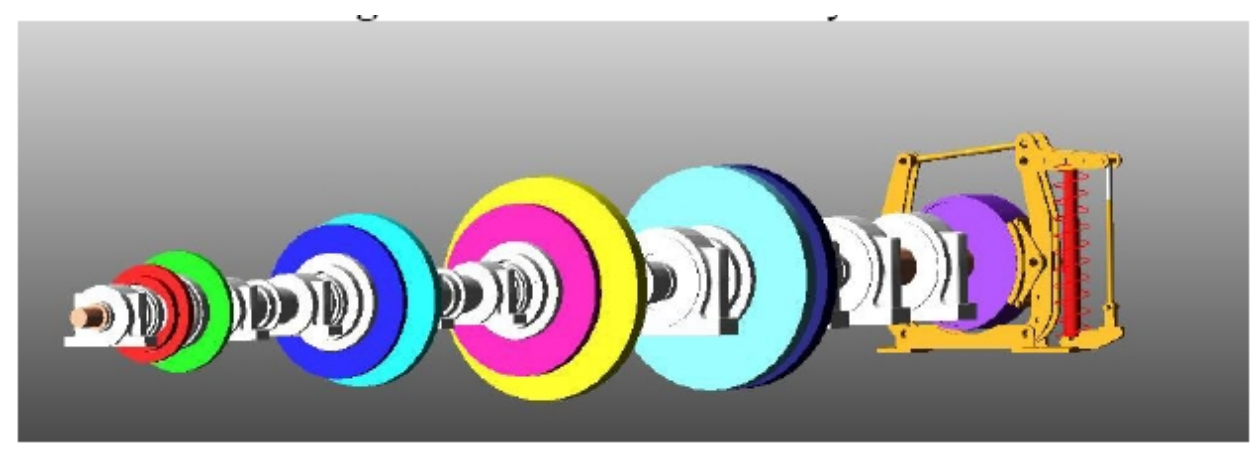

Figure 15. the virtual prototype of inertia test system

At first, the initial rotating speed of main shaft before braking is set on $600 \mathrm{rpm}$, so a speed drive is added to the motor end of main shaft, its speed versus time is shown in figure 16, the speed of main shaft is accelerated from 0rpm to 600rpm during 0s-0.3s, then the speed drive is removed and the whole system is rotating freely during $0.3 \mathrm{~s}-0.54 \mathrm{~s}$, when the brake starts at $0.54 \mathrm{~s}$, the speed of whole system is rapidly decreased to $0 \mathrm{rpm}$ in $0.7 \mathrm{~s}$, and the variation of dynamic torque is recorded in the fixed joint that connects the drum and main shaft. Meanwhile, a simulation script is set up to realize this process in ADAMS, which is shown in Fig. 17. The contact is inactive from 0s to 0.54s, so the speed of main shaft is accelerated to 600rpm, and the contact is active from $0.54 \mathrm{~s}$, thus the drum brake is braking at $0.54 \mathrm{~s}$. In order to consistent with the dynamic braking torque of crane brake type test, the coefficients of contact in ADAMS are carefully adjusted according the length of braking time in type test, and the damping of spring is also adjusted for suppressing the brake's vibration caused by dynamic positive force and friction force. The practical speed of main shaft versus time during barking is shown at figure 18, the braking process is lasting about $0.7 \mathrm{~s}$, thus the braking period of simulation is also adjusted to $0.7 \mathrm{~s}$ in Fig. 16.

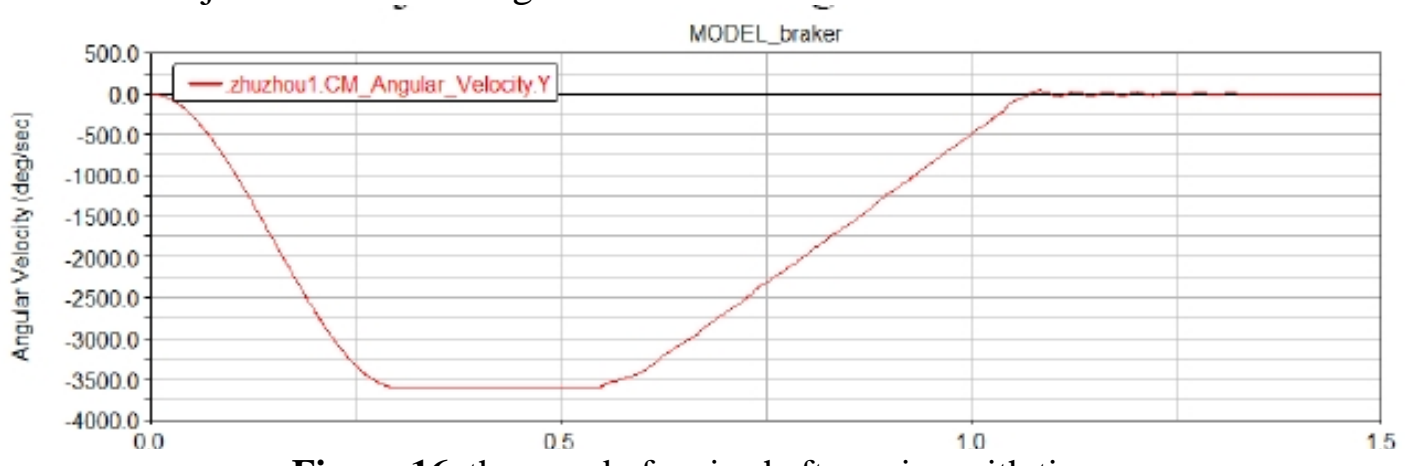

Figure 16. the speed of main shaft varying with time

\begin{tabular}{|c|}
\hline 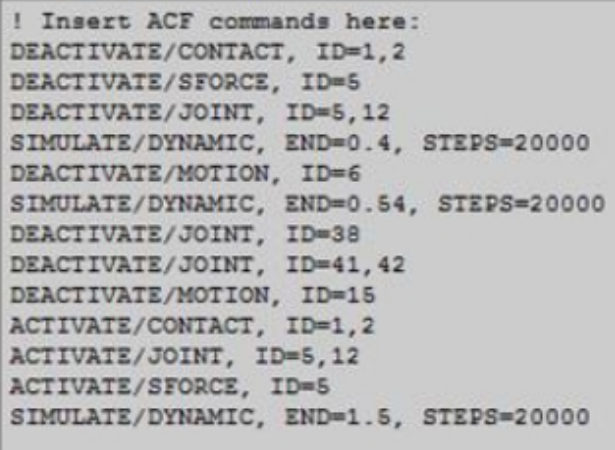 \\
\hline
\end{tabular}

Figure 17. the simulation script 


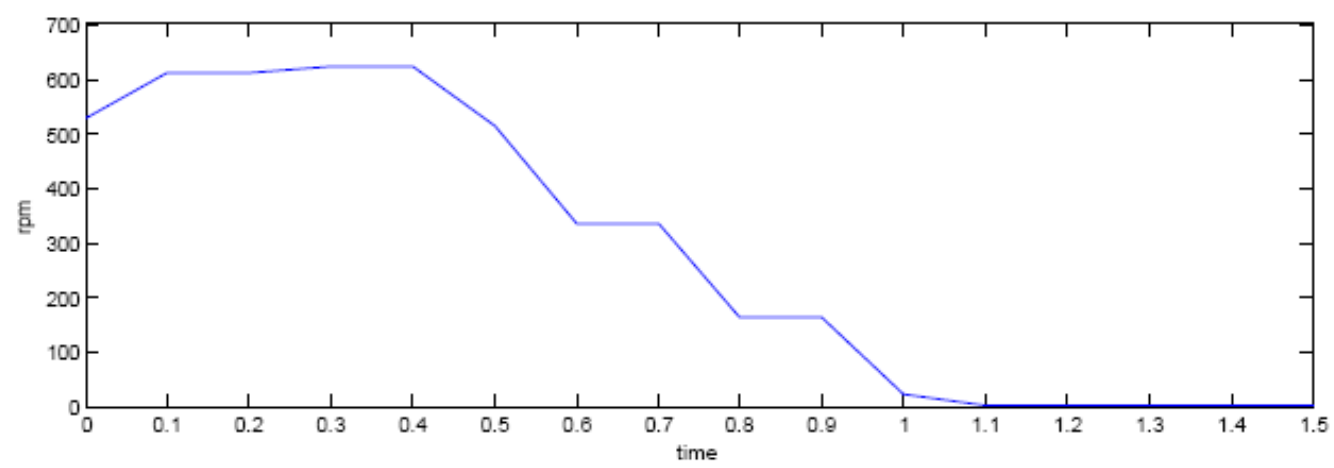

Figure 18. the practical speed of main shaft versus time

The practical dynamic braking torque versus time is shown in figure 19, when the brake starts at $0.2 \mathrm{~s}$, the practical dynamic braking torque is rapidly increased to $4361 \mathrm{Nm}$ at $0.4 \mathrm{~s}$, then the speed of main shaft begin to decrease $335 \mathrm{rpm}$ at $0.6 \mathrm{~s}$, and between $0.6 \mathrm{~s}$ and $0.8 \mathrm{~s}$ the dynamic braking torque reaches to its maximum5762Nm. When the speed of main shaft is lower than $163 \mathrm{rpm}$, the dynamic braking torque becomes falling, finally the speed and torque are almost reaching to zero at same time. In order to observe the relation between different speed and torque, we set the initial speed of the inertia test system from 200rpm to 600rpm, the practical speed of main shaft and dynamic torque during braking are shown in figure $20 \& 21$ respectively. The faster initial speed is, the longer braking time is needed, and the dynamic braking torque is independent of initial speed in a certain range, in Fig. 21 the highest torque among different initial speed is almost equal at about $5800 \mathrm{Nm}$, and the faster initial speed is accompanied with the longer duration of dynamic torque.

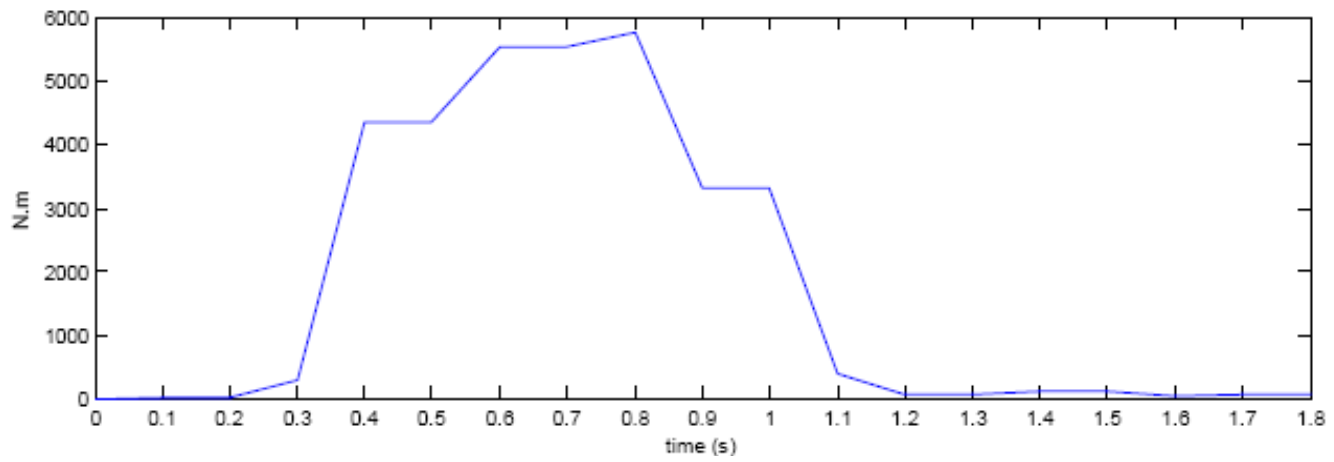

Figure 19. the practical dynamic braking torque at $600 \mathrm{rpm}$ versus time

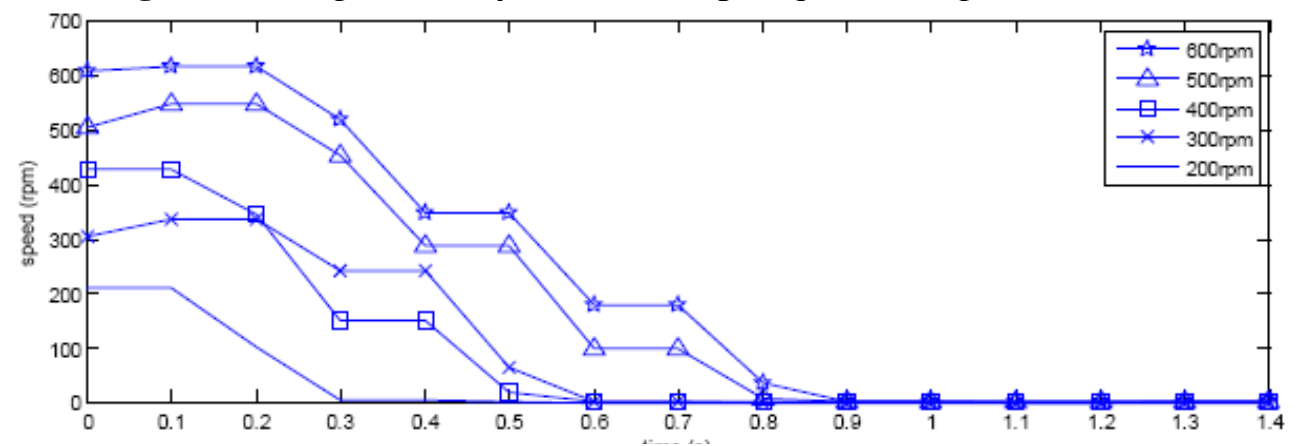

Figure 20. the practical different speeds versus time 


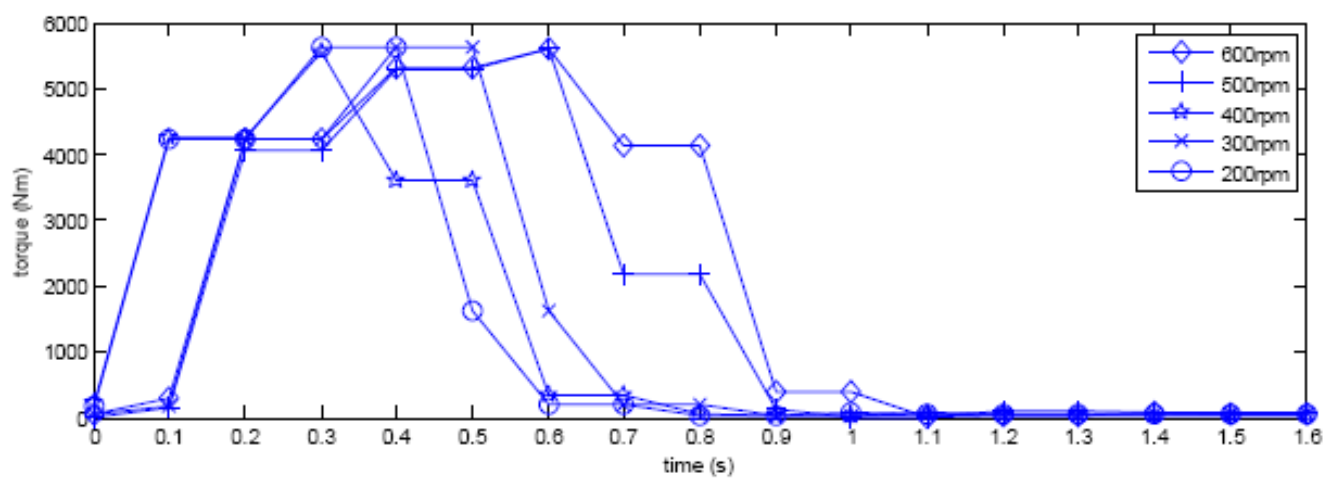

Figure 21. the practical dynamic braking torque of different speeds versus time

In order to verify the virtual prototype of inertia test system, the simulations of dynamic braking torque at different initial speeds are executed, and the static and dynamic coefficients in contact between brake drum and shoes are individually set to 0.349 and 0.26 . The rigid model is adopted in the simulation because of less calculation with better results, and in Fig. 22 the dynamic braking torques of different speeds are displayed, the middle of curves are the variations of torques during braking, the amplitudes of braking torques are almost equal to $5800 \mathrm{Nm}$, which is consistent with the practical dynamic braking torques of different speeds.

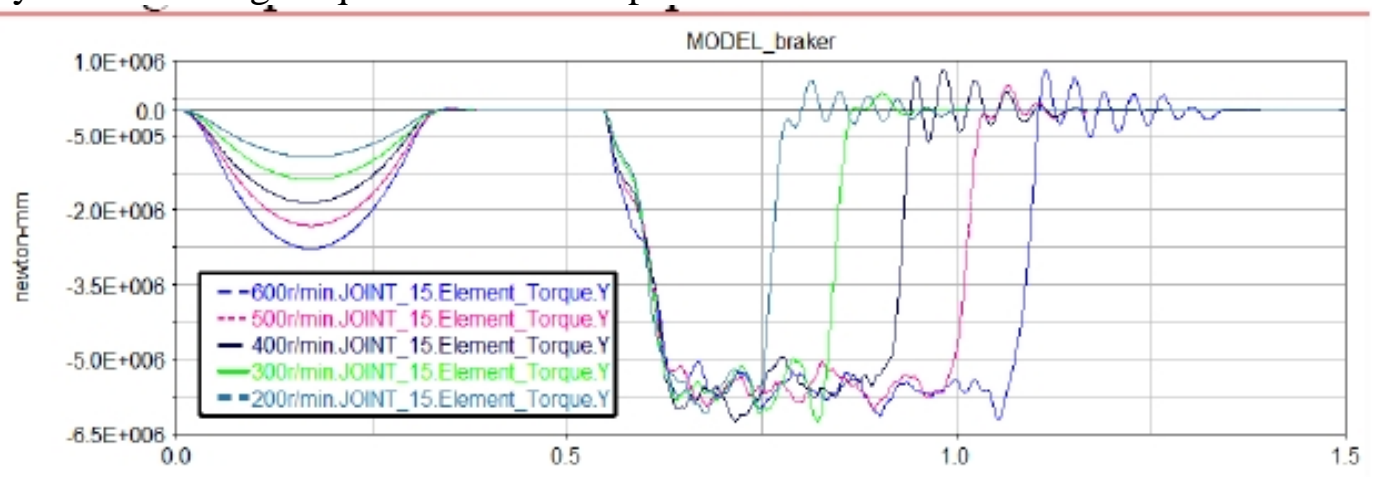

Figure 22. the dynamic braking torques of different speeds versus time

\section{Conclusion}

In the paper, the static and dynamic friction coefficients of crane brake are researched by multibody dynamic ADAMS software. Firstly the virtual prototypes of static and dynamic braking torque test are built according to the crane brake's type test, next by reducing the static friction coefficient, the minimum static friction coefficient is found in simulation of the practical static braking torque, then the relation of practical dynamic braking torques with different initial speeds are invested, meanwhile, the simulation of dynamic braking torques versus different speeds are also invested, which is consistent with each other. In this way, the virtual prototype of crane brake can substitute the practical crane type test in a certain range.

\section{Acknowledgments}

This work was financilly supported by the Science and Technology plan project of General Administration of Quality Supervision, Inspection and Quarantine of P.R.C (Research on crane structural fatigue life intelligent prediction \& assessment 2014QK145, Research on the safety supervision technology of large crane based on big data technology 2015QK053, and Development of intelligent test system for brake motor 2016QK152 ) 


\section{Reference}

[1] Ning Xiaobing, Zhang Wenmin, Simulating analysis on braking efficiency factor of mining truck drum brake, Nonferrous Metals, 57(2),103-110,( 2005).

[2] Ning Xiaobing, The research of heavy truck brake based on virtual prototype technology,Ph.D. Thesis, University of Science and Technology Beijing, (2004).

[3] Lü Zhenhua, Han Wenmin, An analysis on nonuniformity of pressure distribution over friction linings of drum brake shoes, Automotive Engineering, 26 (1),240-244, (2004).

[4] Mao Zhidong, Wang Xuelin, Contact analysis of drum brakes, Journal of Huazhong University of Science and Technology (Natural science edition), 30(7),780-785, (2002).

[5] TSG Q7014-2008, Type test rule for safety accessories and safety protection device for lifting appliances,( 2008). 